\title{
Cuarenta años no son nada: ¿la reposición del clivaje autoritarismo-democracia en el sistema de partidos chileno? ${ }^{1}$
}

\author{
Marcel Aubry* \\ Andrés Dockendorff**
}

\begin{abstract}
Resumen
Con ocasión de la conmemoración de los 40 años del quiebre de la democracia en Chile, una secuencia de eventos ilustra una eventual reposición del clivaje político o división autoritarismodemocracia en el sistema de partidos chileno. Este ensayo se inscribe en una línea argumental alternativa a la de las hipótesis que enfatizan la búsqueda de diferencias sociales estructurales como fundamento de los alineamientos del sistema de partidos, centradas en torno al clásico modelo de Lipset y Rokkan (1967). Aquí se emplea el modelo de full cleavage de Deegan-Krause (2008), que disecciona los clivajes y sus combinaciones posibles en tres dimensiones: socioestructural, normativa y organizacional-institucional. A partir de lo anterior, el artículo provee de plausibilidad a la hipótesis de que la reposición de la división autoritarismo/democracia se da al menos en dos elementos de lo que constituye un clivaje pleno: en los alineamientos ideológicos y en la organización del sistema de partidos. Dado lo anterior, se constata el papel determinante de la agencia política depositada en las élites partidistas para mantener con vida este tipo de conflictos. Esto resulta concordante con lo propuesto hace una década por Torcal y Mainwaring (2003). En cuanto a las implicancias comparativas de la aplicación de la teoría de los clivajes sociales al caso chileno, se advierte el problema potencial de darle un alcance general a la misma, dejándose instalada la interrogante sobre la pertinencia de usar estos conceptos en la realidad latinoamericana de forma acrítica.
\end{abstract}

Palabras clave: Clivajes - sistema de partidos - autoritarismo - élites - agencia política.

\begin{abstract}
On the occasion of the commemoration of the 40th anniversary of the breakdown of democracy in Chile, a sequence of events illustrates a possible replacement of the political cleavage or the authoritarianism-democracy division in the Chilean party system. This essay is part of an alternative line of argument to the hypothesis that emphasize the search for social structural differences as the basis of the alignments of the party system, centered around the classical model of Lipset and Rokkan (1967). Here the full cleavage model of Deegan-Krause (2008) is used, which dissects the cleavages and their possible combinations in three dimensions: socio-structural, normative and organizationalinstitucional. From the above, the article provides plausibility to the hypothesis that the replacement of the division authoritarianism/democracy is given in at least two elements of what constitutes a full cleavage: in the ideological alignments and in the organization of the party system. Given this, the decisive role of political agency placed on party élites to keep alive these kind of conflicts is proved. This is consistent with what was proposed a decade ago by Torcal and Mainwaring (2003). As for the comparative implications of the application of the theory of social cleavages to the Chilean case, the potential problem of giving it a general scope is observed, leaving the question about the relevance of using these concepts in the Latin American reality in an uncritical way.
\end{abstract}

Keywords: Cleavages - party systems - authoritarianism - élites - political agency.

1 Agradecemos los comentarios de Ricardo Gamboa, Alfredo Joignant, Lorena Recabarren y Marcos Barretto.

* Master y PhD (c) en Political Behaviour, University of Essex, Reino Unido. Correo electrónico: maubry@uc.cl

** Magíster en Ciencia Política, Universidad de Chile. Correo electrónico: dockendorf@gmail.com 


\section{INTRODUCCIÓN}

Cuando se cumplieron en 2003 los 30 años del quiebre de la democracia en Chile, todavía se discutía sobre la persistencia de un alineamiento en torno a la valoración del autoritarismo y de la democracia. De tal forma, la derecha continuaba representando casi exclusivamente a quienes apoyaron al régimen de Pinochet, mientras que la Concertación agrupaba a quienes se opusieron.

Paralelamente, un conjunto de decisiones y estrategias de las élites partidistas Ilevaron a un aparente debilitamiento de este conflicto. En la elección de 1999, la derecha ya comienza a avanzar en un proyecto de mayoría, que involucraba dejar atrás la figura de Pinochet. Lo anterior, apostando a una nueva plataforma discursiva orientada a ampliar el apoyo electoral de dicho sector por la vía de reducir el componente ideológico. Esta estrategia se basaba en el supuesto de que el conflicto en torno al autoritarismo decaería con el paso del tiempo.

Finalmente, la llegada a La Moneda del primer presidente socialista después de Allende conllevó la eliminación de los principales enclaves autoritarios mediante las reformas constitucionales de 2005. Con ello, se sustrajo de su dimensión proyectiva a la división en torno al autoritarismo y la democracia. Ello, toda vez que la transición a la democracia en 1990, el cambio de régimen político, así como sucesivos cambios institucionales posteriores dieron por finalizadas querellas políticas para efectuar reformas en torno a dicho conflicto. Es decir, la agenda de democratización dejó de ser un tema de futuro y se transformó en un problema eminentemente anclado en la valoración del pasado.

Este aparente debilitamiento del conflicto en torno al autoritarismo se vio confirmado por el triunfo de Sebastián Piñera en la elección presidencial de 2009. En esa ocasión, la antigua Alianza por Chile, que aglutinaba a los sectores tradicionales de la derecha, se complementa con grupos, dirigentes y adherentes prominentes escindidos de la Concertación. Así, surge entonces la Coalición por el Cambio, que suma a Chile Primero (con Fernando Flores, exministro de Allende) y al PRI (con Adolfo Zaldívar, expresidente de la Democracia Cristiana), entre otros. Al asumir Piñera la primera magistratura, se añade el nombramiento en la cartera de Defensa Nacional del exministro Jaime Ravinet, destacado militante de la Democracia Cristiana. Todas estas son decisiones específicas que buscaban ampliar las bases de apoyo de la derecha más allá de los límites dados por los alineamientos cristalizados con el plebiscito de 1988 .

Lo anterior permitía especular que se estaba en vías de superar definitivamente la estructuración del sistema partidista en torno a Pinochet. En ese sentido, una lectura atenta de la plataforma discursiva de la derecha en la campaña de 2009 demuestra la ausencia de referencias explícitas a temas o asuntos relativos al denominado clivaje autoritarismo-democracia.

No obstante, en 2013 el fundamento de este alineamiento seguía latente, y aún más, fue reposicionado con fuerza por las élites. Ello, tanto por acciones de la Concertación como del Presidente de la República. La oposición dio énfasis al conflicto para dotarse de coherencia y unidad interna. Más que cualquier agenda socioeconómica o cultural, 
lo que los partidos de la "Nueva Mayoría" (ex-Concertación) tienen en común es su condición de opositores a Pinochet. A su vez, el Presidente enfatizó la división para tratar de acentuar su propia identidad dentro de la derecha. Con ello, consiguió polarizar a su sector. Porque, finalmente, al tratar de deshacer la identidad entre Pinochet y la derecha que él representaría, Sebastián Piñera produjo conflicto al interior de esta. Las decisiones y el discurso público del Presidente y de la oposición de centroizquierda en torno a los 40 años del golpe de Estado contribuyeron a dar mayor prominencia al clivaje plebiscitario. Así, se confirma la importancia de la élite como impulsora de la vigencia de las divisiones políticas o ejes de conflicto.

De esa forma, este ensayo explora la posibilidad de que durante 2013, producto de la conmemoración de los 40 años del colapso del régimen democrático, las élites políticas reposicionaron la división autoritarismo-democracia. Para este efecto, se conecta literatura dispersa que alude directa o indirectamente a la discusión de los clivajes al tocar aspectos como: la estructuración programática de los partidos políticos; la conducta electoral; la institucionalización del sistema de partidos; y los efectos del sistema electoral. Luego, para dotar de plausibilidad a la hipótesis, se recoge la secuencia de hechos que provee evidencia sobre la reposición de una división autoritarismo-democracia y su correlato en términos de la opinión pública. Este ensayo intenta contribuir al debate sobre la continuidad de los alineamientos políticos -tanto en términos institucionales como masivos- pese al tiempo que ha pasado desde la restauración democrática.

En consecuencia, se defiende la idea de que las divisiones políticas tienen la capacidad de reproducirse en el tiempo. De igual forma, se argumenta que la división adquiere una inercia que es animada por secuencias de eventos o hitos, como la conmemoración de los 40 años del quiebre de la democracia que tuvo lugar durante 2013. Lo anterior, precisamente bajo el primer gobierno de derecha elegido mediante las urnas desde 1958. Gobierno cuya base de apoyo partidista estuvo conformada por contingente parlamentario y dirigentes que, en su mayoría, apoyaron al régimen militar. Ahora bien, a medida que la experiencia autoritaria que dio origen a la división consecuente se aleja en el tiempo, dicha controversia parece transformarse en algo cada vez más endógeno de la élite política. Esto ocurriría, sin perjuicio de que la opinión pública siga dislocada en torno a asuntos como: la interpretación histórica del quiebre de la democracia, las graves violaciones a los derechos humanos y la figura de Pinochet.

\section{MARCO CONCEPTUAL}

El estudio de la configuración de los sistemas de partidos se ha desarrollado, en buena medida, en torno al trabajo de Lipset y Rokkan (1967). Ellos formularon la noción original de clivajes sociales (del inglés cleavage) o fisuras sociales generativas que explican la formación de los sistemas de partidos en Europa occidental. En términos generales, los autores establecieron la existencia de cuatro grandes clivajes configurados a partir de los procesos de industrialización y construcción del Estado-Nación: la fisura centro-periferia; el conflicto Estado-Iglesia; urbano-rural y, finalmente, el clivaje trabajadores-empleadores. 
En todos esos casos, la fisura refiere a una división fundamental que da lugar a grupos enfrentados, donde las líneas del conflicto siguen características sociales de la población. Luego, emergen partidos políticos representantes de cada uno de los lados del clivaje.

Un elemento central de la noción de clivaje tiene que ver con el momento en que se produce el congelamiento del sistema partidista en torno a líneas de fractura específicas. Así, los partidos que surgen permanecen aún a pesar del debilitamiento de la división original que sirvió de base a su aparición. Ello es posible tanto por razones institucionales propias de la dinámica de la competencia partidista, como por el hecho de que la relación entre los partidos y sus bases sociales de apoyo no es puramente funcional, sino que es mediada por un alineamiento ideológico que se constituye en forma dependiente de la división social.

La teoría de Lipset y Rokkan es específica respecto de las divisiones que dieron origen a los partidos en Europa occidental. Para efectos de hacer esta teoría generalizable a otros sistemas de partidos, sean estos posteriores a los indicados o bien pertenecientes a otros Estados no considerados originalmente, se ha separado la teoría en dos componentes. Por un lado, está el planteamiento formal respecto de la lógica de surgimiento de partidos en torno a divisiones sociales de base. Por otro, se han propuesto otras fuentes de división que dan a lugar a clivajes en diferentes sistemas políticos. Así, adicionalmente a las revoluciones industrial y nacional, que dan origen a los cuatro clivajes clásicos, la literatura también recoge subsecuentes transformaciones que ocasionarían nuevas fisuras generativas, como la revolución postindustrial y el conflicto entre valores materialistas y posmaterialistas aparejado a la misma (Caramani, 2010: 239-242).

En este ensayo adoptamos el esquema que propone Deegan-Krause (2008). En él se busca superar el uso genérico de la noción de clivaje. Allí se segmenta este tipo de divisiones en tres elementos según la conceptualización original de Bartolini y Mair (1990): estructura, actitudes e instituciones. La estructura refiere a grupos sociales definidos funcionalmente y que son bases de construcción identitaria para los individuos. Es decir, grupos asociados a características sociales independientes de la presencia de organizaciones políticas. El elemento de actitudes consiste en normas, valores e ideologías que conforman las principales divisiones en la opinión pública y que señalizan las diferentes opciones políticas. Por último, el elemento institucional corresponde a la provisión de una oferta política (típicamente partidos políticos) que estructura las opciones en la competencia electoral.

De esa forma, el 'clivaje pleno' (full cleavage) contendría los tres elementos señalados precedentemente. Es decir, grupos sociodemográficos con valores característicos asociados a diferentes organizaciones políticas que articulan su representación. Generalmente, la literatura que estudia los sistemas partidistas a partir de la teoría de los clivajes sociales recoge casos en los que uno o dos de los elementos que conforman un clivaje pleno están ausentes (Deegan-Krause, 2008).

En consecuencia, lo que se requiere es de herramientas que permitan analizar "algo menos que un clivaje" (Deegan-Krause, 2008: 539). Así, es posible identificar la presencia de solo una categoría, la cual se denomina "diferencia"; estructural, institucional o actitudinal, 
o de dos de estas, lo que corresponde a una "división" (véase Cuadro 1). En este último caso, las combinaciones de elementos de clivaje posibles serían: estructura más actitudes; estructura más instituciones; y actitudes más instituciones (Deegan-Krause, 2008: 539). De lo anterior se desprende que, como será demostrado en este ensayo, para el caso chileno lo más adecuado desde el punto de vista teórico sería hablar de la "división autoritarismodemocracia" (A/D).

\section{CUADRO 1}

Nomenclatura de divisiones políticas según concurrencia parcial de los componentes de un clivaje pleno

\begin{tabular}{|l|l|l|l|}
\hline & $\begin{array}{c}\text { DIFERENCIA } \\
\text { ESTRUCTURAL }\end{array}$ & $\begin{array}{c}\text { DIFERENCIA } \\
\text { ACTITUDINAL }\end{array}$ & $\begin{array}{c}\text { DIFERENCIA } \\
\text { INSTITUCIONAL }\end{array}$ \\
\hline Diferencia estructural & & & \\
\hline Diferencia actitudinal & División posicional & & \\
\hline Diferencia institucional & División censal & División temática & \\
\hline
\end{tabular}

Fuente: Deegan-Krause (2008).

\section{LA DISCUSIÓN SOBRE EL CASO CHILENO}

Desde una perspectiva histórica existe consenso en la literatura al atribuir al sistema de partidos chileno una morfología básica que lo emparenta más con sus homólogos europeos que con los discontinuos sistemas partidistas latinoamericanos, caracterizados por el caudillismo y la liquidez de sus estructuras de división (Dix, 1989; Gil, 1969; Coppedge, 1998; Roberts y Wibbels, 1999: 587). Corrientemente, se afirma que el sistema partidista chileno se habría organizado en torno a clivajes de largo plazo (Scully, 1992; Valenzuela, 1995; Dix, 1989). Esta semblanza europea también se manifestaría en lo referido al alto nivel de institucionalización (Mainwaring y Scully, 1995).

La temprana formación de un sistema partidista nacional y la eficacia del esquema de representación fueron rasgos distintivos del proceso político chileno antes del derrumbe de la democracia. Así, los partidos habrían conformado junto a otras organizaciones la "columna vertebral" del sistema político (Garretón, 1983: 17).

El surgimiento del sistema de partidos chileno puede explicarse mediante el planteamiento de Lipset y Rokkan para las democracias avanzadas (Scully, 1992). Conforme a esta interpretación, el multipartidismo chileno surge de conflictos secuenciales que dividen el espacio político, incorporando dimensiones sucesivamente. Así, el conflicto clerical-secular en el siglo XIX estructuró el sistema de partidos en forma tripartita, con radicales, liberales y conservadores. El conflicto de clases urbano, en la primera mitad del siglo XX, dio lugar a los partidos de izquierda (Socialista y Comunista), obligando al desplazamiento del Partido 
Radical al centro político. En la segunda mitad del siglo XX, la extensión del conflicto de clases al sector rural habría dado paso al surgimiento del Partido Demócrata Cristiano en el centro del sistema de partidos (Scully, 1992).

Con todo, sin perjuicio del número de partidos, en el período pre-1973 el sistema partidista chileno se habría configurado en torno a tres tercios nítidos: izquierda, centro y derecha (Gil, 1969: 263; Valenzuela y Valenzuela, 1983; Valenzuela, 1978; Valenzuela, 1995; Scully, 1995; Tironi y Agüero, 1999). Lo anterior, bajo una clara preeminencia del clivaje de clases por sobre la fisura religiosa precedente (Bustamante, 1991: 29).

Al menos en lo referido a las etiquetas partidarias habría una continuidad relevante entre el sistema de partidos anterior a 1973 y el posterior a 1988. Lo novedoso es el reacomodo que operan esos partidos tradicionales en términos de conglomerados permanentes desde 1990. La principal característica del sistema de partidos que surge luego del régimen de Pinochet es su estructura en dos capas. Así, pese a existir un multipartidismo de base, sobre esto se monta una estructura con dos bloques permanentes, denominados la Alianza y la Concertación ${ }^{2}$. Estos forman, en esa capa, un sistema de partidos cuasi-bipartidista, en atención al peso electoral de ambos bloques en conjunto. Esta estructura surge con ocasión del plebiscito de 1988, de modo tal que la Concertación, hoy "Nueva Mayoría", ha aglutinado a los principales partidos por el No, mientras que la Alianza agrupa a los partidos más relevantes por el Sí. Ambos bloques persisten desde entonces solo con variaciones menores. Es importante llamar la atención al hecho de que este agrupamiento se ha mantenido para presentar candidaturas en todos los niveles ${ }^{3}$. Lo anterior, independientemente del sistema electoral que rija en cada caso: mayoritario (elección presidencial y de alcaldes desde 2000), proporcional de dos escaños (elecciones parlamentarias) y proporcional propiamente tal (elección de concejales).

Esta estructura doble del sistema de partidos es compatible a simple vista con diversas estructuras de división de base. Por un lado, la posición de los partidos, así como su agrupamiento en dos bloques, es comprensible por referencia al sistema de partidos existente hasta 1973, de modo tal que los bloques se componen con dos tercios en un lado y un tercio en el otro, partiendo desde la estructura surgida con ocasión del conflicto de clases. Pero, por otro lado, es también comprensible como un resultado del agrupamiento establecido en torno al plebiscito de 1988.

Con todo, ¿cuál eje divisorio predomina en el nuevo sistema de partidos chileno? ¿Las tradicionales divisiones socioeconómicas pre-1973, o la división A/D? En trazos gruesos, y a riesgo de pasar por alto diferencias sustantivas entre ellos, diversos autores han defendido

2 Durante la competencia electoral, desde 1989 la centroizquierda se ha etiquetado bajo el nombre de "Concertación de Partidos por la Democracia", hoy "Nueva Mayoría". Por su parte, la coalición que aglutina a los partidos de derecha ha tenido varias denominaciones: "Unión por el Progreso"; "Unión por Chile"; "Alianza por Chile"; "Coalición por el Cambio", y nuevamente Alianza por Chile.

3 Al tomar como unidad de análisis a las alianzas, y no a los fuerzas partidistas individuales, la estabilidad de los alineamientos políticos en el caso chileno es mucho más alta en perspectiva comparada (Morgenstern et al., 2012; Carreras et al., 2013: 8). 
la continuidad de los clivajes históricos luego de la interrupción autoritaria (Valenzuela, 1995, 1999; Scully, 1995; Valenzuela y Scully, 1997; Raymond y Barros, 2012; Scully y Valenzuela, 1993; Valenzuela et al., 2007; Dow, 1998). En esa línea, opinión experta a inicios de los noventa consideraba la dimensión socioeconómica (rol del Estado) como la más relevante para comprender los alineamientos en el sistema de partidos chileno (Huber e Inglehart, 1995).

Mientras tanto, otros investigadores discuten la noción de continuidad planteada más atrás, y postulan que el eje autoritarismo-democracia constituye un nuevo clivaje político capaz de explicar la configuración del sistema partidista post-Pinochet (Torcal y Mainwaring, 2003; Siavelis, 2000; Carreras et al., 2013; Bonilla et al., 2011; Tironi et al., 2001; Carey, 2002; Tironi y Agüero, 1999; Álvarez y Katz, 2009; Bonilla y Silva, 2008). En ese sentido, también se ha señalado que la adhesión y cooperación entre partidos al mismo lado del clivaje de régimen podría terminar socavando la fisura de clase precedente (Siavelis, 2000: 121).

El planteamiento sobre el rol del autoritarismo en la conformación del sistema de partidos es introducido y masificado en la literatura por Tironi y Agüero (1999). Estos autores especularon que los clivajes sociales clásicos habrían perdido la capacidad estructurante, siendo desplazados por un nuevo alineamiento asociado al legado autoritario. Así, postulan que el alineamiento surgido en 1988 estaría fuertemente anclado en una división social, de modo tal que no operaría solamente en el nivel de los partidos, sino que también entre el público masivo (p. 158). En este sentido proponen el asentamiento del Ilamado "clivaje autoritarismo-democracia", el que sería del mismo tipo que las divisiones sociopolíticas propuestas por Lipset y Rokkan. Las razones que argumentan son tres (p. 157). Primero, los alineamientos nuevos aparecerían como consecuencia de un quiebre profundo del régimen democrático en 1973. Segundo, la experiencia autoritaria constituiría un marco político de referencia para toda una generación de individuos, que se consolida como opciones políticas organizadas en el plebiscito de 1988. Tercero, este alineamiento sobreviviría por largo tiempo gracias a los intentos periódicos que efectúan los partidos para rescatarlo, así como por el efecto de los arreglos institucionales que encuadran la competencia partidista (particularmente, el sistema binominal). Entonces, los autores estarían proponiendo que el alineamiento que ensambla las valoraciones sobre el autoritarismo y la democracia constituye un "clivaje pleno", ya que se desplegaría en las tres dimensiones mencionadas en la sección anterior, a saber: estructura, instituciones y actitudes.

Estas ideas fueron criticadas, sosteniéndose que no se ajustan correctamente a la teoría de los clivajes sociales a la cual los autores recurren para fundamentar su argumento. Así, la oposición entre autoritarismo y democracia sería solo un alineamiento político de carácter transitorio, y en ningún caso un clivaje o fisura generativa en los términos planteados por Lipset y Rokkan en su trabajo original (Valenzuela, 1999; Ortega, 2003; Siavelis, 2000; Valenzuela et al., 2007; Maillet, 2009). La razón sería que este alineamiento del sistema de partidos no sería el reflejo de identidades de base que estructuren el conflicto social por medio de expresiones diversas, entre las cuales se cuenten partidos representativos de esos grupos. En otras palabras: "una fisura social/histórica se ramifica en la formación de toda una serie 
de instituciones sociales, lo que proporciona el sustrato a lo que viene a ser una subcultura e identidad colectivas" (Valenzuela, 1999: 279). De manera adicional, sería teóricamente innecesario postular una nueva forma de división para explicar la permanencia de partidos suficientemente entendida en referencia a los clivajes clásicos religioso-secular y de clase.

En otras palabras, de acuerdo con el esquema propuesto por Deegan-Krause, el reacomodo de los partidos en dos coaliciones permanentes correspondería solo a una diferencia institucional o, a lo sumo, a lo que se denomina como una división temática (dada por la concurrencia entre una diferencia actitudinal y una diferencia institucional, sin contarse con una diferencia estructural). Es por ello que en este ensayo se sugiere que la noción de "división A/D" captura de mejor manera los postulados de la teoría original, al mismo tiempo que reconoce el efecto operado en el sistema de partidos chileno por dicho alineamiento. Lo anterior coincide con el juicio de que, si bien el sistema partidista posautoritario ha cambiado significativamente respecto al precedente, es "(...) poco probable que haya surgido una nueva fisura con suficiente fuerza como para reorganizar el panorama político chileno" (Scully, 1995: 101).

Determinar si la diferencia actitudinal autoritarismo-democracia está vigente o no, constituye otra línea de pesquisa más específica. Se ha planteado que en la medida en que: el período autoritario comenzara a quedar atrás; los militares pasaran a estar sujetos al control civil; los enclaves autoritarios fueran eliminados; el sistema electoral binominal fuese reformado; y fechas simbólicas como el 11 de septiembre perdieran prominencia, la división entre quienes apoyaron y rechazaron al régimen de Pinochet se debilitaría como elemento explicativo de la institucionalización del sistema de partidos y la movilización electoral (Valenzuela y Scully, 1997; Angell, 2003: 102; Luna y Altman, 2011; Ruiz, 2005).

Siguiendo esos planteamientos, los resultados de las elecciones de 2009, en las que la Alianza derrotó a la centroizquierda, reflejarían el declive de los ejes de conflicto que han explicado la competencia política después del régimen de Pinochet, incluida la división asociada al régimen (Luna y Mardones, 2010). Al mismo tiempo, con la victoria del RN Sebastián Piñera, la derecha habría encontrado al "mensajero" capaz de desvincular a la coalición del legado del autoritarismo (p. 116). Estos asuntos serán retomados más adelante en este ensayo.

\subsection{Evidencia empírica para el caso chileno: ¿herencia política del autoritarismo?}

Probablemente, es al trabajo de Torcal y Mainwaring (2003) al que se deba reconocer la más completa y detallada defensa de la idea de que la división en torno al régimen de Pinochet es capaz de estructurar el sistema de partidos ${ }^{4}$. Los autores defienden la capacidad explicativa de los legados políticos del autoritarismo en el sistema de partidos de la democracia restaurada. Ellos argumentan que el caso chileno demostraría la posibilidad

4 Para una evaluación del argumento de Mainwaring y Torcal a la luz de la literatura sobre partidos y elecciones en Chile, véase Joignant (2007). 
de que la morfología del sistema de partidos se vea afectada seriamente por la herencia política del período autoritario. Esto habría devenido en un clivaje entre quienes apoyaron y quienes se opusieron al régimen de Pinochet. A objeto de fundamentar su argumento, Torcal y Mainwaring proponen llevar la mirada a las élites y a su capacidad para moldear el sistema de partidos durante los períodos de transición ${ }^{5}$.

A estos autores les preocupa un problema teórico mayor, cual es si el origen de los clivajes políticos requiere de divisiones socioestructurales en su base o si las élites pueden fabricarlos "desde arriba" (lo cual constituye la diferencia entre un "clivaje pleno" y una "división" en el sistema de partidos). Conforme a su conceptualización, habría tres vías diferentes para comprender el surgimiento de los clivajes políticos. Primero, la perspectiva en que el cambio social deviene en alineamientos políticos. Segundo, aquella en que dicho cambio conlleva transformaciones en valores o ideología, los cuales, a su vez, resultan en una reconfiguración del sistema partidista. Tercero, los autores proponen la posibilidad de que los clivajes en el sistema de partidos sean consecuencia de una creación política y no necesariamente surjan "desde abajo".

Estos autores argumentan que en el caso chileno, el alineamiento en torno al autoritarismo desplaza a las otras fuentes de división política y, por ende, constituye un ejemplo de un clivaje constituido puramente por efectos de agencia política. Siguiendo a Bartolini y Mair (1990), proponen que esta segmentación en torno al régimen político tendría los tres elementos de un clivaje (p. 77). Es decir, se contaría con una diferencia estructural de base, con alineamientos actitudinales de los grupos en oposición y con la articulación política dada por la división en el sistema de partidos (p. 80).

La organización del sistema de partidos digitada por las élites "desde arriba" sería un rasgo definitorio del sistema de partidos post-Pinochet. Ello habría sido facilitado por la naturaleza de la transición a la democracia (pp. 80-83). Por una parte, los líderes opositores habrían funcionado con bastante autonomía respecto de la sociedad civil y de las mismas orgánicas partidistas. En la otra vereda, los dos nuevos partidos de la derecha, Renovación Nacional (RN) y la Unión Demócrata Independiente (UDI), se crearon siguiendo esa misma lógica top down, que se señaló precedentemente.

El completo trabajo de Torcal y Mainwaring ha servido como un punto de referencia obligado para desarrollos posteriores de componente empírico sobre este debate. Tres estudios han tratado de actualizar las conclusiones con datos más recientes y técnicas diferentes. El primero, usando datos de la elección de 2005 (elecciones presidencial y legislativa), concluye que el principal determinante de la decisión de voto está asociado con la dimensión autoritarismo-democracia. Allí se constata entonces que la división no ha perdido influencia (Álvarez y Katz, 2009). Un segundo estudio evalúa empíricamente las hipótesis de clivajes sociales y de clivajes políticos a partir de las diferentes situaciones

5 Sobre el rol de las élites y la agencia política, véase Chhibber y Torcal (1997). Ahí, los autores argumentan, tomando el caso español, cómo a las decisiones estratégicas de las élites partidistas van aparejadas determinadas configuraciones del sistema de partidos y los grupos sociales que respaldan a los partidos que lo conforman. 
de polarización en el electorado que cada una implica. El resultado sería consistente con la hipótesis de los clivajes políticos de Torcal y Mainwaring, encontrando a los votantes divididos unidimensionalmente en dos grupos (Bonilla et al., 2011) ${ }^{6}$.

En tercer lugar, el reciente trabajo de Bargsted y Somma (2013) da cuenta de un proceso paulatino de desalineamiento entre preferencias políticas y divisiones de clase, religión y régimen. El alto grado de convergencia alcanzado a nivel de la élite en torno a los asuntos señalados habría debilitado la señalética de la dimensión normativo-ideológica, para usar las categorías de Bartolini y Mair. En particular, estos autores asignan un peso mayor a la estructura de incentivos que delimita la competencia política. Tanto la moderación de la izquierda en el gobierno, como la progresiva desvinculación de los partidos de derecha con el régimen militar y con la figura de Pinochet, habrían contribuido a desanclar el clivaje de clase a nivel masivo (Bargsted y Somma, 2013).

Conforme a esta interpretación, la mantención de un clivaje sería tributaria de la capacidad o el interés de las élites políticas por señalizar las coordenadas del sistema partidista a través de la ideología, manteniendo la división a nivel del público masivo. Esto va en línea con lo apuntado sobre la importancia de la agencia política para la reproducción de los ejes de conflicto (Torcal y Mainwaring, 2003; Chhibber y Torcal, 1997).

La discusión sobre el mecanismo causal propio de la división $\mathrm{A} / \mathrm{D}$ se discontinúa luego del trabajo de Torcal y Mainwaring. A excepción de los tres trabajos citados arriba, la literatura posterior alude a dinámicas potencialmente asociadas a dicha división sin reexaminar sus fundamentos teóricos ni aportar nueva evidencia que discuta el núcleo de la polémica en torno a la prevalencia de una u otra división en el Chile post-Pinochet.

\section{LA SECUENCIA DE EVENTOS DE 2013: CUARENTA AÑOS DESPUÉS}

En 2013 se cumplieron 40 años del quiebre de la democracia en Chile. Con motivo de dicha fecha, canales de televisión abierta y los principales medios de prensa escrita cubrieron profusamente diversos aspectos relativos a: el proceso de polarización política vivido durante el gobierno de Salvador Allende, el golpe de Estado, el régimen autoritario y las violaciones a los derechos humanos. Testimonios de actores claves, así como de personas que vivieron dicho período histórico, activaron una fuerte agenda medial en torno a la conmemoración del 11 de septiembre. Lo anterior, algo quizás comparable solamente a lo vivido con ocasión de los 30 años de la misma fecha, en 2003, durante el gobierno del socialista Ricardo Lagos Escobar.

Desde los partidos y representantes de la ex-Concertación de Partidos por la Democracia y el Partido Comunista, ahora agrupados en la "Nueva Mayoría", se había esbozado

6 Recientemente, Kenneth Roberts ha argumentado que la fortaleza y estabilidad de un clivaje de régimen entre partidarios y opositores a los regímenes militares en América Latina se profundiza si existe un partido de izquierda significativo que, dejando atrás objetivos revolucionarios, ha adoptado la democracia como la única institucionalidad aceptable (Roberts, 2013: 20-22). 
la importancia y simbolismo de esta fecha. Como recoge la prensa de esas semanas, principalmente entre agosto y septiembre se registró un nutrido debate entre actores políticos y académicos sobre el rol de los distintos actores en el quiebre de la democracia. Por ejemplo, trayendo a colación la denominada "Carta de los 13", donde un grupo de militantes del Partido Demócrata Cristiano (PDC) condenó el golpe de Estado a dos días del 11 de septiembre de 1973.

El alineamiento institucional del PDC con la intervención militar, así como el análisis retrospectivo de la posición asumida por la Falange fueron motivo de discusión al interior del partido, así como también de debate con dirigentes de otros partidos de la "Nueva Mayoría". La colaboración de militantes del partido en el régimen militar, o bien el apoyo a la Declaración de la Cámara de Diputados de agosto de 1973, en la que se acusaba al gobierno de "haber quebrantado la institucionalidad", causaron polémica en la coalición de centroizquierda. Ahora bien, la directiva del PDC desechó la idea de realizar una actividad propia con motivo de los 40 años de la fecha señalada, optando por sumarse al acto a realizarse en conjunto con los demás partidos que conforman la "Nueva Mayoría" (La Tercera, 6 de septiembre de 2013).

Anteriormente, a fines de junio de 2013, las dos coaliciones realizaron primarias legales vinculantes para seleccionar a sus candidatos presidenciales. En el caso de la "Nueva Mayoría", una observación rápida de la prensa de la época demuestra la existencia de acentuadas diferencias programáticas, específicamente entre el PDC y una parte de la izquierda, que apoyaba la opción de la ex-Presidenta Michelle Bachelet. Las desavenencias eran principalmente sobre temas como: matrimonio homosexual; aborto; educación particular subvencionada y asamblea constituyente. En términos generales, y con énfasis diferenciados, el bloque Partido Socialista (PS), Partido por la Democracia (PPD) y Partido Comunista (PC) impulsaba dichas propuestas. Mientras tanto, el PDC, que respaldaba la candidatura del exalcalde Claudio Orrego, se oponía.

Aquellos temas asociados a la división A/D, como: la oposición a la figura de Pinochet, las violaciones a los derechos humanos, el debate en torno al sistema político institucional y al modelo económico heredado del régimen militar se constituyeron en el único factor en común entre todas las candidaturas presentadas por los partidos de la "Nueva Mayoría" al proceso de primarias. Como ya se señaló, una vez superadas dichas elecciones, el discurso en torno a los 40 años del quiebre de la democracia cobró inusitada fuerza, animado por una abundante cobertura mediática.

Hasta ese punto, el debate en torno al autoritarismo parecía radicado casi en forma exclusiva en personeros y representantes de la centroizquierda, sin perjuicio de que estuviera presente con fuerza en las líneas editoriales de los principales medios de comunicación nacionales. Como se sostuvo en la introducción de este artículo, los partidos de la derecha ya habían adoptado la estrategia de dejar atrás la figura de Pinochet, así como la defensa explícita del régimen militar. No obstante, la intervención del Presidente de la República, el RN Sebastián Piñera, dotó al debate de una impensada dinámica. Como veremos a continuación, esto sirvió para reponer la división A/D. 


\subsection{Los cómplices (pasivos) del Presidente}

A fines de agosto de 2013, el Presidente Piñera otorgó una entrevista en la que acuñó el término "cómplices pasivos". Esto, a objeto de enfatizar la responsabilidad que tendrían los civiles que apoyaron al régimen militar en las violaciones a los derechos humanos. La entrevista que dio Sebastián Piñera al diario La Tercera gatilló un conjunto de reacciones y alineamientos en la élite político-partidista. En la entrevista, Piñera señaló que:

“(...) si buscamos responsables de lo ocurrido durante el gobierno militar y, particularmente, de los atropellos a los derechos humanos y la dignidad de las personas, por supuesto que hay muchos. Por de pronto, las máximas autoridades del gobierno militar, que sabían o debían saber lo que estaba ocurriendo. Pero no solamente ellos. Hubo muchos que fueron cómplices pasivos: que sabían y no hicieron nada o no quisieron saber y tampoco hicieron nada" (La Tercera, Reportajes, 31 de agosto de 2013).

Al atribuir responsabilidades a civiles bajo la figura de "cómplices pasivos", Piñera importó al interior de la alianza de gobierno la polémica en torno al golpe de Estado y el régimen autoritario posterior. Lo anterior, toda vez que muchos de los civiles aludidos de manera indirecta hoy forman parte de los cuadros directivos y parlamentarios de los partidos de derecha, en particular de la UDI (Joignant y Navia, 2003). Inclusive, prominentes miembros del gabinete del gobierno de Sebastián Piñera fueron funcionarios de gobierno durante el régimen autoritario, o bien respaldaron públicamente a Pinochet en momentos en que las violaciones a los derechos humanos eran conocidas en el mundo entero ${ }^{7}$.

De paso, lo anterior confirmaría que la división en torno al régimen militar causa mayor polarización al interior de la alianza de partidos derechistas (Ruiz, 2005). Con todo, no se registró mayor respaldo a los dichos del Presidente en las declaraciones de dirigentes y parlamentarios de los partidos de derecha. Esto se entiende observando las palabras del mismo Sebastián Piñera, cuando señala que: "(...) casi toda la centroderecha se inclinó en esa época por el Sí. Yo lo discutí mucho" (La Tercera, Reportajes, 31 de agosto de 2013).

Sebastián Piñera explicó, en la misma entrevista, que su alineamiento como opositor a Pinochet -que según declaró también se tradujo en votaciones en contra en la consulta de 1978 y en el plebiscito por la Constitución de 1980-, no le impidió integrar un partido que apoyó la opción Sí en 1988, como es RN:

"Así que no es solo que voté No en el 88. Voté No en el 78 y en el 80. Sin embargo, una cosa es recuperar la democracia, que era mi gran motivación, y otra muy distinta es qué quería para el futuro de mi país. Y por eso, cuando finalmente se recuperó la democracia, tomé el camino que todos conocen" (La Tercera, Reportajes, 31 de agosto de 2013).

7 En esta categoría entran cómodamente los siguientes ministros de Estado del gobierno de Piñera: el Ministro del Interior y militante UDI Andrés Chadwick; el Ministro Secretario General de la Presidencia Cristián Larroulet y el Ministro de Educación y también militante UDI Joaquín Lavín. 
Estas palabras dan cuenta de un intento por seccionar o parcelar el clivaje. Por un lado, en cuanto al apoyo-oposición a Pinochet, el actual mandatario se ubica al lado del No ("recuperar la democracia"). Esto, a diferencia de gran parte de la derecha. Mientras tanto que respecto del ámbito programático, excluidas aquellas materias referidas a la división A/D (derechos humanos, enclaves autoritarios, por mencionar algunos), su domicilio estaría con la alianza derechista ("(...) lo que quería para el futuro de mi país"). Cabe poner en duda si dicha segmentación de la dimensión ideológico-programática haya sido posible en plena transición a la democracia, cuando los asuntos referidos a la división A/D conformaban las principales querellas políticas por resolver. Actualmente, como se concluye, separar el clivaje no es posible. Ello, debido a que la división A/D posee una connotación eminentemente retrospectiva. Es decir, refiere principalmente a valoraciones sobre el pasado, y no a alternativas de política pública o disputas políticas que obligan a tomar posición sobre temas de futuro.

Una muestra de declaraciones de actores políticos representantes de los partidos de derecha ilustran la polarización causada por las palabras del Presidente Piñera. Dirigentes que se han caracterizado por su férrea defensa del régimen de Pinochet salieron a intentar trazar una línea entre lo que habría sido el apoyo al autoritarismo y el voto por la opción Sí, por un lado, de las violaciones a los derechos humanos, por otro. Para el entonces diputado UDI Iván Moreira: "nadie desconoce los desaparecidos ni el tema de los derechos humanos, pero no hay que olvidar que el 73 éramos ellos o nosotros", y que "votar por el Sí no era justificar cualquier abuso a los derechos humanos que haya habido" (La Tercera, Reportajes, 31 de agosto de 2013). El senador UDI Jovino Novoa también criticó duramente al Presidente y su ofensiva en materia de derechos humanos en torno al 11 de septiembre:

"No es legítimo usar términos ambiguos como el de 'cómplices pasivos'. (...) Venir ahora, 20, 30 o 40 años después, cómodamente sentado a decir que quienes debieron haber hecho esto o lo otro me parece a mí que es absolutamente injusto e irresponsable".

Además, dijo considerarse: "(...) un actor muy activo" durante los tres años que le correspondió estar en el Gobierno "para que Chile pudiera aprobar un camino para llegar a la democracia" (El Mercurio, 6 de octubre de 2013).

El presidente de la UDI, Patricio Melero, alcalde designado de Pudahuel entre 1985 y 1989, también aludió a la participación de civiles en el gobierno militar, y al efecto que tenían las palabras del Presidente: "Me dolió a mí, y a muchos chilenos, que Piñera hablara de cómplices pasivos porque deslegitima lo que mucha gente de derecha ha hecho por el país. Hubo un aporte nuestro muy importante" (Biobío Chile, 7 de octubre de 2013).

\subsection{El cierre del penal Cordillera}

A la entrevista en la que se acuña el término "cómplices pasivos", le seguiría otra decisión que impactó por su simbolismo y las posiciones divididas que generó al interior de la derecha. El 27 de septiembre, luego de una polémica entrevista concedida por el exjefe de la Dirección de Inteligencia Nacional (DINA), Manuel Contreras, el Presidente Piñera anunció el cierre del penal Cordillera. Este penal había sido construido durante 
el gobierno de Ricardo Lagos para albergar a militares condenados por violaciones a los derechos humanos. Esta decisión motivó inesperados alineamientos en el discurso de los partidos que conforman la Alianza, reflotando ejes de conflicto, que al menos en cuanto a su prominencia, parecían enterrados ${ }^{8}$.

Aquí parecen de interés las declaraciones del Ministro de Defensa, Rodrigo Hinzpeter, estrecho colaborador de Sebastián Piñera, y considerado en algún momento como heredero de un proyecto político que se pensaba sería trascendente a un solo periodo gubernamental. Este aludió a la imposibilidad de proyectar políticamente a la derecha sin desprenderse de los denominados legados autoritarios:

“(...) yo tengo la impresión de que no existen posibilidades de proyectar un sector político sobre bases que tienen debilidades en puntos que me parecen éticos (...) tengo la impresión que muchas veces el sector de la centro derecha no ha hecho la pérdida y el costo definitivo de que algunos de sus integrantes hayan sido partidarios del régimen militar y eso se ha terminado convirtiendo en una debilidad crónica para nuestro sector" (La Segunda, 30 de septiembre de 2013).

En el fondo, se sigue de este discurso que la cancelación de los vínculos con el régimen militar sería determinante para la competitividad del sector en lo sucesivo, asunto que no había sido planteado previamente en esos términos de forma explícita. Esto, a pesar de que como se señaló, la alianza derechista comienza un proceso de desacople con la figura de Pinochet desde fines de los 90. Los dirigentes de la Alianza reaccionaron fuertemente a las declaraciones del Ministro de Defensa, acusando al gobierno de: “(...) seguir haciéndole el juego a la Concertación (...) estamos pegados, para beneficio de la Nueva Mayoría, en una discusión de temas del pasado" (Emol, 30 de septiembre de 2013). En un comité político de La Moneda realizado en esos días, representantes de los partidos oficialistas habrían planteado, además, que el énfasis en la conmemoración de los 40 años tendrá un impacto en las elecciones parlamentarias, donde se perdería voto "duro" del sector, tanto de militares como de civiles (La Segunda, 30 de septiembre de 2013).

Respecto de la dimensión proyectiva que puso de relieve el Ministro de Defensa, actores como el senador UDI Jovino Novoa respondieron sosteniendo que deviene en un imposible dar proyección política a un sector a partir de la negación del pasado. Un pasado, además, "en el cual la mayoría de los actuales dirigentes de la centroderecha tuvieron participación. Además, la modernización llevada a cabo durante ese gobierno corresponde a nuestro ideario" (Qué Pasa, 3 de octubre de 2013).

En declaraciones correspondientes a esas mismas semanas, el diputado UDI Ernesto Silva sostuvo que el proyecto político de la Alianza estaba liderado por la derecha popular articulada por la UDI, vinculada estrechamente a una historia de líderes de ese partido que habrían tenido gran participación en "las transformaciones" del régimen de Pinochet (Qué

8 Uno de los exuniformados que iba a ser trasladado desde el penal Cordillera a la cárcel de Punta Peuco, el general (r) Odlanier Mena, se quitó la vida antes de que dicho traslado se materializara. 
Pasa, 3 de octubre de 2013). En una posición intermedia se manifestó la senadora RN Lily Pérez. Resaltando la vigencia de la división $A / D$, manifestó que:

“El eje no es si alguien participó, apoyó o simpatizó con el gobierno militar. Si no, tendríamos que pensar en vivir artificialmente en otro país. Sobre todo considerando que en 1988, la votación entre Sí y No se dividió casi en partes iguales. La realidad es que Chile durante largo tiempo fue un país dividido entre dos sectores políticos polarizados que hoy se siguen expresando a través de un sistema electoral binominal" (Qué Pasa, 3 de octubre de 2013).

En definitiva, tanto el reposicionamiento del discurso en torno al quiebre de la democracia, los graves atropellos a los derechos humanos y el autoritarismo, así como decisiones concretas tomadas durante 2013, demuestran la capacidad de reproducción de la división A/D. En particular, relevan la pertinencia de considerar con mayor atención el papel que juega la "agencia política" en el campo de la investigación en torno a los clivajes y el sistema partidista.

Con todo, esta serie de eventos adquiere una connotación especial al tratarse de un año en el que concurren elecciones presidenciales y parlamentarias. Ello, al menos teóricamente, favorece la alineación de las diferencias ideológica e institucional. Lo señalado implica que existiría una división ideológica basal que se expresa en un arreglo partidista específico. Ello, no obstante, siempre en ausencia de grupos sociales con características específicas alineados a cada lado de la división. A continuación se revisan estos asuntos.

\section{LAS DIMENSIONES DE LA DIVISIÓN EN CHILE}

Volviendo al marco teórico propuesto al inicio del ensayo, al hablar de un clivaje político en los términos que aquí se interpreta la propuesta de Torcal y Mainwaring, esto correspondería a una división temática. En otras palabras: ‘algo menos que un clivaje'. Una división temática se caracteriza por una diferencia estable entre los partidos que es acompañada por una diferencia ideológica que sigue las mismas líneas partidarias. Eso significa que la división no requiere fundarse en una diferencia de base en la estructura social. En otras palabras, la "división $\mathrm{A} / \mathrm{D}$ " no constituiría la politización de un conflicto social, como sí lo fueron el conflicto religioso o de clases en el pasado. Ambas diferencias se examinan en esta sección.

\subsection{Dimensión normativo-ideológica de la división}

La dimensión normativo-ideológica de la división refiere a la diferencia presente en las élites y en el electorado entre líneas ideológicas asociadas al conflicto principal. Para dotar de fundamento a la diferencia ideológica, es necesario que se presente una polarización en la opinión pública en los mismos términos que los alineamientos partidistas. Ya Huneeus (2003) y Huneeus y Maldonado (2003) examinaron en detalle la incidencia del régimen militar y temas relacionados en la opinión pública. Allí encontraron notables diferencias respecto de la valoración de la democracia, de la evaluación del quiebre de 1973, del régimen posterior y de la agenda asociada a los derechos humanos. La información descriptiva que se presenta a continuación reafirma, diez años después, la porfiada persistencia de dichas valoraciones. Con todo, debe advertirse nuevamente 
que esta polarización del público masivo no debe entenderse como una diferencia basal en la estructura social.

Aquí se recurre a datos proporcionados por la encuesta del Centro de Estudios de la Realidad Contemporánea (CERC) y de la Encuesta Bicentenario, ambas de 2013. De las dos fuentes se concluye que en 2013 continuaba vigente la división en la opinión pública. Es decir, las opiniones sobre asuntos relacionados con la división A/D se corresponden con la identificación política. Ello, como se señaló arriba, a una década de la conmemoración anterior del quiebre del régimen democrático. Se presentan algunos datos seleccionados sobre dos asuntos específicos: por un lado, la correlación entre alineamientos políticos y opiniones sobre el autoritarismo. Por otra parte, cuánto inciden esos alineamientos en las generaciones más recientes de ciudadanos, quienes no estuvieron políticamente activos al momento de congelarse la estructura de pactos en el sistema de partidos.

En primer lugar, hay información suficiente para afirmar que la evaluación del golpe de Estado sigue líneas partidarias robustamente por sobre el margen de error. Los datos de la encuesta CERC, resumidos en el Cuadro 2, muestran que en 2013 hay diferencias claves entre quienes se identifican con los partidos de la Alianza y quienes se identifican con los partidos de la ex-Concertación. Esto se expresa en la evaluación sobre: Augusto Pinochet; Salvador Allende; la justificación del golpe de Estado; el significado de este en términos históricos; y la evaluación del autoritarismo.

\section{CUADRO 2}

Opiniones sobre el autoritarismo según identificación partidaria (2013) (\%)

\begin{tabular}{|l|c|c|c|c|c|c|}
\hline Principal responsable del golpe de Estado: Pinochet & UDI & RN & PDC & PPD & PS & TOTAL \\
\hline Principal responsable del golpe de Estado: Allende & 9 & 18 & 48 & 68 & 51 & 41 \\
\hline Los militares tenían razón para dar el golpe de Estado & 69 & 52 & 7 & 8 & 5 & 24 \\
\hline $\begin{array}{l}\text { El 11 de septiembre de 1973 liberó a Chile del marxismo } \\
\text { El general Pinochet pasará a la historia como un dictador }\end{array}$ & 69 & 53 & 10 & 5 & 7 & 18 \\
\hline $\begin{array}{l}\text { El general Pinochet pasará a la historia como uno de los } \\
\text { mejores gobernantes del siglo XX }\end{array}$ & 43 & 31 & 1 & 2 & 1 & 96 \\
\hline
\end{tabular}

Fuente: Encuesta CERC (2013).

Los resultados anteriores se complementan con algunas opiniones sobre la agenda actual relativas al autoritarismo, reparaciones a víctimas de violaciones a los derechos humanos y otros. La Encuesta Bicentenario de la Universidad Católica (UC) incluyó algunas 
preguntas al respecto. En el Cuadro 3 se resumen algunas de estas, dividiendo la muestra según identificación política en el eje izquierda-derecha. El resultado es que, en forma consistente con los datos presentados anteriormente, la evaluación de los temas en agenda sobre los 40 años también sigue líneas ideológicas. En efecto, quienes se identifican con la derecha concuerdan en mayor proporción que quienes lo hacen con la izquierda, en que "El país debería dar vuelta la página y no seguir enfrentándose a causa de lo que ocurrió en 1973" (71\% contra 38\%, respectivamente). Lo mismo ocurre con la pregunta sobre si "El Estado chileno ya ha hecho lo suficiente para reparar el daño que se infligió a las víctimas" (51\% contra 20\%, respectivamente). En sentido contrario, existen mayores niveles de concordancia entre quienes se identifican con la izquierda en lo referente a destinar recursos a homenajes y reparaciones para las víctimas de los atropellos a los derechos humanos.

\section{CUADRO 3}

Opiniones sobre el legado autoritario según identificación política (2013) (\%)

\begin{tabular}{|l|c|c|c|c|c|}
\hline & IZQUIERDA & CENTRO & DERECHA & NINGUNA & TOTAL \\
\hline $\begin{array}{l}\text { El país debería dar vuelta la página y no } \\
\text { seguir enfrentándose a causa de lo que } \\
\text { ocurrió en } 1973\end{array}$ & 38 & 46 & 71 & 52 & 49 \\
\hline $\begin{array}{l}\text { El Estado chileno debería insistir en nuevas } \\
\text { formas de reparación a los familiares de los } \\
\text { detenidos-desaparecidos }\end{array}$ & 61 & 44 & 30 & 44 & 46 \\
\hline $\begin{array}{l}\text { El Estado debe financiar memoriales o } \\
\text { monumentos que rindan homenaje a las } \\
\text { víctimas de violaciones a los derechos } \\
\text { humanos }\end{array}$ & 45 & 37 & 21 & 30 & 35 \\
\hline $\begin{array}{l}\text { El Estado chileno ya ha hecho lo suficiente } \\
\text { para reparar el daño que se infligió a las } \\
\text { víctimas }\end{array}$ & 20 & 31 & 51 & 24 & 30 \\
\hline
\end{tabular}

Fuente: Encuesta Bicentenario UC (2013).

La segunda arista sobre los resultados en el nivel del público masivo dice relación con la mantención de la prevalencia de ciertas opiniones dentro de las nuevas generaciones. Existe la idea, aquí rebatida, de que en las elecciones de 2009 emergió un clivaje generacional, que se montaría y luego comenzaría a desplazar la división del Sí-No (Navia y Schuster, 2011). Para las mismas preguntas seleccionadas anteriormente, se presenta el resultado global según grupos de edad. Como se muestra, no hay una diferencia importante entre grupos etarios. Es decir, la prevalencia global de ciertas opiniones es relativamente homogénea entre todos los 
grupos de edad. Por ejemplo, en el caso de establecer "el principal responsable del golpe de Estado", mientras en el total de la población el $41 \%$ dice que fue el general Pinochet, en el grupo de menor edad esta opinión alcanza al $47 \%$. Así también, la frase "El general Pinochet pasará a la historia como un dictador" obtiene un $76 \%$ de apoyo globalmente, el cual es de $67 \%$ en el grupo de menor edad. En síntesis, en ninguna de las preguntas reportadas hay una diferencia mayor a $9 \%$ entre el resultado general y el resultado en el grupo de 18 a 25 años, que corresponde al tramo etario que tiene mayor distancia generacional con los eventos referidos.

\section{CUADRO 4}

Opiniones sobre el autoritarismo según grupos de edad (2013) (\%)

\begin{tabular}{|l|c|c|c|c|c|}
\hline & $18-25$ & $26-40$ & $41-60$ & 61 Y MÁS & TOTAL \\
\hline Principal responsable del golpe de Estado: Pinochet & 47 & 43 & 40 & 36 & 41 \\
\hline Principal responsable del golpe de Estado: Allende & 6 & 8 & 8 & 16 & 9 \\
\hline Los militares tenían razón para dar el golpe de Estado & 11 & 13 & 20 & 21 & 16 \\
\hline El 11 de septiembre de 1973 liberó a Chile del marxismo & 13 & 16 & 20 & 25 & 18 \\
\hline El general Pinochet pasará a la historia como un dictador & 67 & 79 & 78 & 75 & 76 \\
\hline $\begin{array}{l}\text { El general Pinochet pasará a la historia como uno de los } \\
\text { mejores gobernantes del siglo XX }\end{array}$ & 5 & 9 & 10 & 6 & 9 \\
\hline
\end{tabular}

Fuente: Encuesta CERC (2013).

Al igual que antes, se cuenta con la división en grupos de edad de las opiniones sobre los temas de futuro. De la misma forma que en los temas anteriores, no parece haber diferencias importantes en la distribución de las opiniones entre los diferentes grupos generacionales (Cuadro 5). Es el caso, por ejemplo, de "dar vuelta la página" sobre 1973, donde el acuerdo con la afirmación propuesta es de $49 \%$ en general y $43 \%$ entre los menores de 25 años. Ocurre lo mismo con el financiamiento de monumentos $(46 \%$ contra $45 \%)$ y con crear nuevas formas de reparación ( $46 \%$ contra 45\%).

Un segundo elemento que puede ilustrar la dimensión normativo-ideológica de la organización analítica propuesta por Deegan-Krause es el despliegue de los partidos políticos en el continuo izquierda-derecha. Si se observa la autopercepción de las élites parlamentarias, los partidos políticos registran un alto grado de estabilidad en cuanto a su ubicación en dicho espectro. No se aprecian desviaciones relevantes, y quizás el desplazamiento más notorio en el tiempo sea la inclinación de la UDI hacia posiciones más centristas (Alcántara, 2012). 
CUADRO 5

Opiniones sobre el legado autoritario según grupos de edad (2013) (\%)

\begin{tabular}{|l|c|c|c|c|c|c|}
\hline & $18-24$ & $25-34$ & $35-44$ & $45-54$ & 55 Y MÁS & TOTAL \\
\hline $\begin{array}{l}\text { El país debería dar vuelta la página y no seguir } \\
\text { enfrentándose a causa de lo que ocurrió en 1973 }\end{array}$ & 43 & 50 & 52 & 43 & 48 & 49 \\
\hline $\begin{array}{l}\text { El Estado chileno debería insistir en nuevas } \\
\text { formas de reparación a los familiares de los } \\
\text { detenidos-desaparecidos }\end{array}$ & 45 & 48 & 43 & 47 & 46 & 46 \\
\hline $\begin{array}{l}\text { El Estado debe financiar memoriales o } \\
\text { monumentos que rindan homenaje a las víctimas } \\
\text { de violaciones a los derechos humanos }\end{array}$ & 33 & 39 & 31 & 33 & 37 & 35 \\
\hline $\begin{array}{l}\text { El Estado chileno ya ha hecho lo suficiente para } \\
\text { reparar el daño que se infligió a las víctimas }\end{array}$ & 27 & 26 & 32 & 34 & 30 & 30 \\
\hline
\end{tabular}

Fuente: Encuesta Bicentenario UC (2013).

Junto a la estabilidad de las coaliciones, cabe señalar que el sistema de partidos posPinochet también estaría dotado de una continuidad ideológica y nivel de representación política superior a la media de la región (Luna y Zechmeister, 2006; Alcántara y Luna, 2004). Esto, acompañado de una tendencia general de moderación y proximidad programática en comparación al período previo al quiebre de la democracia (Angell y Pollack, 1995; Gamboa et al., 2013; Castillo et al., 2013; Carreras, 2012: 141-142).

\subsection{Dimensión institucional de la división}

La dimensión institucional refiere a la provisión de partidos políticos. Esto supone que hay partidos asociados al autoritarismo y otros a la democracia, al menos en términos de su posición original al momento de la coyuntura crítica. De acuerdo con la teoría, dichos partidos mantienen esa posición en el tiempo, aunque se debilite o pierda fuerza el fundamento basal.

En el período pre-1973, los tres tercios obtienen una votación más o menos equivalente. Mientras tanto, en la democracia reinaugurada se aprecia una tendencia a la erosión del centro político, representado anteriormente por el PDC, pero que debe agruparse electoralmente con las formaciones de izquierda. Mientras tanto, la derecha y la izquierda ven incrementado su caudal electoral. Ello echa por tierra la hipótesis de continuidad histórica de los tres tercios (Valenzuela y Scully, 1997). El debilitamiento del tercio de centro se acentúa en las elecciones legislativas no concurrentes de 2001, en el segundo año del gobierno de Ricardo Lagos. Mientras tanto, ya en 1997 la UDI mostró un notable crecimiento, en buena medida a expensas de RN y del PDC (Huneeus, 2002). 
Dos decisiones estratégicas adoptadas por las élites partidistas contribuyen a mantener la diferencia partidista A/D. Primero, la reciente incorporación del PC a la "Nueva Mayoría". Si bien se requiere un análisis más exhaustivo de los discursos y documentos programáticos de cada partido ${ }^{9}$, el principal elemento en común entre el PC y los partidos de la ex Concertación es su calidad de opositores al régimen de Pinochet. Esto denota la capacidad estructurante que conserva la división A/D para la organización del sistema de partidos.

Al mismo tiempo, la decisión del PDC de mantenerse en la Nueva Mayoría, a pesar de las diferencias programáticas que se acentuaron durante el proceso de primarias realizadas en 2013 -en particular en temas como aborto, asamblea constituyente y educación-, da luces sobre el efecto, potencialmente endosable a la división A/D, sobre los alineamientos partidarios. Es decir, si bien es posible argumentar en torno a un aumento de las distancias programáticas al interior de la coalición de centroizquierda, lo concreto es que a diferencia de lo ocurrido hasta 2009, en 2013 el PC apoyó desde la primera vuelta la candidatura de la Nueva Mayoría, y pasa luego a integrar el gobierno con puestos en el gabinete. Es decir, la capacidad de atracción de la división A/D sigue teniendo un rol en las decisiones y posicionamiento de las organizaciones partidistas, y por ende, en el andamiaje del sistema partidista pos-Pinochet.

Con todo, una revisión de la literatura obliga a una mayor cautela en cuanto al impacto de la división A/D en el sistema partidista. En ese sentido, deben ser considerados en el análisis los factores institucionales, como es el sistema electoral binominal para las elecciones legislativas. Se ha sostenido que el sistema binominal genera poderosos incentivos para que los partidos se organicen en dos grandes bloques (Valenzuela, 2005: 54; Rabkin, 1996; Siavelis, 2005a, 2005b; Carey, 2006, 2002; Guzmán, 1993; Zucco, 2007). Bajo esa mirada, el esquema binominal habría sido una "camisa de fuerza" que convierte el multipartidismo chileno en un esquema bipolar (Valenzuela, 2005: 54) ${ }^{10}$. Con ello, según J. Samuel Valenzuela, los arreglos del sistema partidista chileno se entenderían no solo a la luz de la "inercia política" del plebiscito, sino que también de la institucionalidad electoral ${ }^{11}$.

Si lo anterior es cierto, una eventual reforma al sistema electoral binominal debería erosionar las bases de la división A/D. Si se acepta que con el sistema electoral binominal la competencia por el centro se produce al interior de cada coalición, y no en el sistema partidista desplegado "como un todo" (Siavelis, 2005a: 19), resulta plausible una mayor polarización tanto del discurso y apelación de los partidos como también de la demanda electoral.

9 Respecto de la distancia programática en el sistema de partidos chileno a la luz de los manifiestos programáticos, véase Gamboa et al. (2013).

10 Sin perjuicio de lo anterior, al menos entre 1989 y 2001, los incentivos generados por el sistema binominal no habrían logrado operar una disminución en la cantidad de partidos y candidatos parlamentarios (Cabezas y Navia, 2005; Navia, 2005).

11 Ello habría sido un objetivo buscado deliberadamente por las autoridades del régimen militar, que buscaban evitar el multipartidismo del sistema precedente al quiebre de la democracia, y que habría servido a la polarización del sistema político (Valenzuela y Siavelis, 1991). 
Como se vio anteriormente, parte de los investigadores pronosticó un debilitamiento de la división A/D en la medida en que los enclaves autoritarios fuesen eliminados, las causas por derechos humanos se radicaran en la justicia, y la experiencia autoritaria quedara en el pasado. Respecto de lo último, se ha visto aquí que eso no ha ocurrido a nivel de opinión pública. Ahora, ¿qué impacto han tenido los enclaves autoritarios en el proceso político? ${ }^{12}$ Según Edgardo Boeninger, los enclaves no habrían sido efectivos. Las disposiciones de tutelaje militar como el Consejo de Seguridad Nacional o la inamovilidad de los comandantes en jefe no habrían alterado efectivamente el funcionamiento de la democracia. Al mismo tiempo, el avance gradual pero incremental en los procesos por las violaciones a los derechos humanos y la eliminación de los senadores designados les quitarían peso a las disposiciones antidemocráticas legadas por el autoritarismo (Boeninger, 2007: 103-107).

La Ley 20.050, promulgada por el Presidente Ricardo Lagos, operó un conjunto sustantivo de reformas a la Carta Fundamental destinadas a terminar con dichos enclaves: eliminó la figura de los senadores designados y vitalicios; retiró la referencia al sistema binominal de la Constitución; sustrajo a las Fuerzas Armadas el rol de garantes de la institucionalidad; limitó las atribuciones del Consejo de Seguridad Nacional; y terminó con la inamovilidad de los comandantes en jefe.

Con todo, a pesar de cambios como los señalados, que parecían clausurar institucionalmente las querellas político-institucionales referidas a la división $A / D$, hoy resulta evidente que la noción de "enclaves autoritarios" sigue presente en el discurso público. Particularmente, se la utiliza para fundamentar la necesidad de reemplazar la Constitución de 1980 por un nuevo texto, o bien para dar cuenta del origen autoritario que tendrían determinadas políticas económico-sociales y por ende relevar su ilegitimidad y necesidad de cambio. Es decir, la eliminación de varias de las disposiciones más polémicas del texto fundamental por medio de las enmiendas de 2005 no conllevó un debilitamiento de la división A/D, como pronosticaba parte de la literatura. Tampoco, el hecho de que la justicia haya avanzado en juicios por casos de violaciones a los derechos humanos mucho más allá de lo previsto a comienzos de la transición.

\section{CONSIDERACIONES FINALES}

En las secciones anteriores se ha mostrado lo siguiente. Primero, con la conmemoración de los 40 años del quiebre de la democracia vino aparejada una reposición de la división A/D. Segundo, una mirada rápida de datos perceptivos disponibles muestra que la opinión

12 La noción original de "enclaves autoritarios" fue formulada por Garretón (1989). El concepto se compone de tres dimensiones: institucional, actoral y simbólica. Los enclaves institucionales refieren principalmente a la carta fundamental de 1980 y al conjunto de estructuras y disposiciones que contempla dicho texto. Para el autor, resultaban particularmente críticas el conjunto de prerrogativas heredadas por los militares que les conferían capacidad de vetar el proceso político democrático. El segundo enclave está conformado por tres actores que, de acuerdo con Garretón, se "moverían" como enclave: los militares, la derecha política y los empresarios. El tercer enclave, simbólico, corresponde básicamente a las violaciones a los derechos humanos, y los condicionamientos referidos a su reparación y justicia (p. 51-63). 
pública continúa dislocada en torno a los asuntos referentes al quiebre de la democracia. Lo anterior, sea respecto de la evaluación de sus causas como de la calificación de la violación de los derechos humanos y la reparación, entre otros. Esta diferencia se mantiene incluso en las generaciones que no tuvieron experiencia directa en los hechos referidos, y cuya socialización política ocurrió en democracia. Ello da cuenta de la vigencia de una segmentación entre autoritarios y demócratas, al menos en la dimensión normativo-ideológica. En tercer lugar, se expuso que la mantención del agrupamiento de los partidos políticos chilenos en dos coaliciones, que representan los lados de la disputa en torno al régimen militar por sobre otros elementos de la agenda, se fortalece con la unión entre el PC y los partidos de la histórica Concertación.

De los antecedentes presentados anteriormente, resulta viable argumentar que la reposición de la división $\mathrm{A} / \mathrm{D}$ se produce en al menos dos dimensiones que conforman un clivaje propiamente tal: en los alineamientos ideológicos y en la organización de las fuerzas que componen el sistema de partidos. Es decir, los partidos políticos, en forma coherente con las tendencias del electorado, se agrupan conforme a los bandos establecidos en torno a esa coyuntura.

En este punto, es importante advertir una característica distintiva del alineamiento en torno al Sí y al No: la división A/D es fundamentalmente retrospectiva. A diferencia de los clivajes tradicionales, no incide en decisiones políticas de futuro que requieran alineamientos institucionales para su resolución. Un ejemplo es el caso de clivaje secular/clerical. Como lo consigna la historia, el conflicto sobre el rol de la Iglesia vis-à-vis el papel del Estado en el orden social solo deviene en decisiones vinculantes con posterioridad a la coyuntura crítica que le da origen. Primero, con las leyes laicas del período del Presidente Santa María y luego con su resolución constitucional en 1925. Lo anterior se extiende al llamado clivaje de clase, que emerge junto con la clase obrera, cuya agenda se mantiene vigente hasta el quiebre de la democracia.

Esta dimensión proyectiva, que animaba dichas fisuras generativas, está ausente de la división A/D. Esta no involucra decisiones que arbitren el conflicto entre las diferentes bases sociales de apoyo, sino que expresa fundamentalmente la valoración sobre eventos pasados. El contenido o temas que conforman esta división política adquieren entidad solo al traer a tiempo presente decisiones, alineamientos, actitudes o discursos del pasado. En particular en torno al apoyo/rechazo al régimen militar, por un lado, y a la postura frente a las graves violaciones de los derechos humanos, por otro.

Debido a que ya se realizó la transición a la democracia, no hay decisión pendiente sobre el régimen político desde esa perspectiva. Las sucesivas reformas a la Constitución, y en particular las de 2005 que eliminaron los denominados "enclaves autoritarios", así como el hecho de que el problema de las violaciones a los derechos humanos sea hoy resorte de la justicia, sustraen a esta división de una connotación proyectiva desde el punto de vista político. Otros conflictos sobre la calidad de las instituciones o la orientación de las políticas económicas y sociales no necesariamente son expresión de esta fisura. En consecuencia, el que no haya un conflicto prospectivo asociado a la división A/D hace innecesario referirse a ella para efectos de políticas públicas. 
Así, la división A/D requiere que el proceso político la reponga periódicamente. El hecho de que los partidos de la "Nueva Mayoría" aludan al origen autoritario de instituciones y políticas, refleja la necesidad de dotarse de coherencia interna. Es decir, tematizar diversos problemas de política pública como herencias derivadas de un pasado autoritario, permitiendo de paso la convergencia de fuerzas políticas con programas tan distantes como el PDC y el PC. Por el contrario, al menos desde 1999, la estrategia de la derecha fue apostar a que la división decayese en el tiempo por la vía de omitir referencias a esta. Esto coincide con la emergencia, en esas elecciones presidenciales, de una nueva plataforma discursiva en el sector, orientada a ampliar el apoyo popular de la derecha por la vía de reducir el componente ideológico de su discurso. La única vez que una parte de la derecha con la Concertación convergen en la estrategia de establecer explícitamente su posición en torno a la división A/D, es el momento en que el Presidente Piñera decide en 2013 hacer los planteamientos que han sido discutidos aquí, sin perjuicio de los desacuerdos que hubiere en su sector al respecto.

Esto parece confirmar lo planteado hace diez años por Torcal y Mainwaring: la agencia política y las élites tienen un rol determinante en dotar de resiliencia los ejes de conflicto que son factores de división en sistemas de partidos y en el electorado. En el caso examinado aquí, el papel de las élites es aún más importante si se observa que no existen grupos sociales adscritos a cada uno de los lados de la división en función de una diferencia de base. Como se trata de "algo menos que un clivaje", no se está en presencia de la polarización política de un conflicto social precedente. Solamente, se produce una diferencia estable entre organizaciones partidistas seguida por una diferencia ideológica. Es decir, una división temática.

Al mismo tiempo, los enclaves autoritarios no habrían afectado el proceso político como se pronosticó a inicios de la transición. Ello releva aún más la importancia de las élites en mantener con vida los clivajes a partir de su agencia política.

En otro orden de ideas, lo propuesto en este ensayo releva la importancia de considerar las implicancias analíticas y comparadas de este debate. Básicamente, en lo que atañe al problema potencial de tratar de aplicar a los sistemas de partidos latinoamericanos las categorías analíticas desarrolladas para otros contextos. Recordemos que el planteamiento original de Lipset y Rokkan no es genérico ni puramente abstracto. Al contrario, es una teoría fundada históricamente para explicar la estabilidad de los sistemas de partidos que articulan la representación de sociedades divididas por el proceso de desarrollo de sus propios Estados nacionales. Solo posteriormente se le dio un alcance general, pero queda instalada la interrogante sobre el potencial de aplicación de estos conceptos en nuestro contexto. En perspectiva comparada, esta duda se hace extensiva a casos de transición reciente a la democracia, como países de Europa del Este y por cierto de América Latina.

Por ello es que, como se sugiere en este artículo, resulta especialmente conveniente la estructura conceptual propuesta por Deegan-Krause, montada sobre la formalización que Bartolini y Mair hacen del planteamiento original de Lipset y Rokkan. Esta estructura permite mayor flexibilidad en la aplicación de los conceptos originales. Con ello, se comprenden adecuadamente situaciones que no se ajustan al tipo puro de clivaje social, que en la nomenclatura que hemos utilizado corresponde al clivaje pleno. 


\section{BIBLIOGRAFÍA}

Alcántara, M. (2012): “Elections in Latin America 2009-2011: a comparative analysis", Working Paper, \#386-June, Kellogg Institute.

Alcántara, M. y J.P. Luna (2004): “Ideología y competencia partidaria en dos post-transiciones: Chile y Uruguay en perspectiva comparada", Revista de Ciencia Política, XXIV (1), pp. 128-168.

Álvarez, R.M y G. Katz (2009): "Structural cleavages, electoral competition and partisan divide: a Bayesian multinomial probit analysis of Chile's 2005 election", Electoral Studies, 28 (2), pp. 177-189.

Angell, A. (2003): "Party change in Chile in comparative perspective", Revista de Ciencia Política, 23 (2), pp. 88-108.

Angell, A. y B. Pollack (1995): "The Chilean election of 1993: from polarisation to consensus", Bulletin of Latin American Research, 14 (2), pp. 105-125.

Bargsted, M. y N. Somma (2013): "Social cleavages and political dealignment in contemporary Chile, 1995-2009", Party Politics (en prensa).

Bartolini, S. y P. Mair (1990): Identity, competition, and electoral availability: the stabilization of European electorates 1885-1985, Cambridge University Press, Cambridge.

Boeninger, E. (1997): Democracia en Chile. Lecciones para la gobernabilidad, Editorial Andrés Bello, Santiago de Chile.

(2007): Políticas Públicas en democracia. Institucionalidad y experiencia chilena, Uqbar Editores, Santiago de Chile.

Bonilla, C. y E. Silva (2008): "Revisitando la teoría espacial del voto: nueva evidencia sobre Chile al 2003 y sus implicancias para las candidaturas presidenciales del 2005", Estudios Públicos, 109, pp. 268-284.

Bonilla, C., R. Carlin, G. Love y E. Silva (2011): "Social or political cleavages? A spatial analysis of the party system in post-authoritarian Chile", Public Choice, 147, pp. 9-21.

Bustamante, F. (1991): "Sistema de partidos políticos y clivajes electorales en la transición chilena". América Latina Hoy, 2, pp. 27-39.

Cabezas, J. y P. Navia (2005): “Efecto del sistema binominal en el número de candidatos y de partidos en elecciones legislativas en Chile, 1989-2001", Política, 45, pp. 29-53.

Caramani, D. (2010): "Party systems", en D. Caramani (ed.): Comparative politics, Oxford University Press, Oxford, pp. 237-259.

Carey, J. (2002): "Parties, coalitions and the Chilean Congress in the 1990", en S. Morgenstern y B. Nacif (eds.): Legislative politics in Latin America, Cambridge University Press, Cambridge, pp. 222- 253.

(2006): “Las virtudes del sistema Binominal”, Revista de Ciencia Política, 26 (1), pp. 226-235.

Carreras, M. (2012): "Party systems in Latin America after the Third Wave: a critical re-assessment", Journal of Politics in Latin America, 4 (1), pp. 135-153.

Carreras, M., S. Morgensten y S. Yen Pin (2013): "Refining the theory of partisan alignments: evidence from Latin America", Party Politics, 19 (4), pp. 1-15.

Castillo, J., I. Madero-Cabib y A. Salamovich (2013): "Clivajes partidarios y cambios en preferencias distributivas en Chile", Revista de Ciencia Política, 33 (2), pp. 469-488. 
Chhibber, P. y M. Torcal (1997): "Elite strategy, social cleavage and party system in a new democracy: Spain", Comparative Political Studies, 30 (1), pp. 27-54.

Coppedge, M. (1998): "The evolution of Latin American party systems", en S. Mainwaring y A. Valenzuela (eds.): Politics, society, and democracy: Latin America, Westview Press, Boulder, pp. 172-206.

Dalton, R.J. (2006): Citizen politics: public opinion and political parties in advanced industrial democracies, CQ Press, Washington D.C. (4a edición).

Deegan-Krause, K. (2007): "New dimensions of political cleavage", en R.J. Dalton y H.D. Klingemann (eds.): Oxford handbook of political behavior, Oxford University Press, Oxford, pp. 538-556.

Dix, R. (1989): "Cleavage structures and party systems in Latin America", Comparative Politics, 22 (1), pp. 23-37.

Franklin, M.N. (2004): Voter turnout and the dynamics of electoral competition in established democracies since 1945, Cambridge University Press, Cambridge.

Gamboa, R., M. López y J. Baeza (2013): “La evolución programática de los partidos chilenos: 19702009: de la polarización al consenso", Revista de Ciencia Política, 33 (2), pp. 443-467.

Garretón, M.A. (1983): El proceso político chileno, FLACSO, Santiago de Chile. (1989): La posibilidad democrática en Chile, FLACSO, Santiago de Chile.

(1991): "La redemocratización política en Chile. Transición, inauguración y evolución", Estudios Públicos, 42, pp. 102-133.

Garrido, C. y P. Navia (2005): “Candidatos fuertes en la Concertación: ¿seguro para subcampeones o prevalencia de los tres tercios?", Estudios Públicos, 99, pp. 165-194.

Gil, F. (1969): El sistema político de Chile, Editorial Andrés Bello, Santiago de Chile.

Godoy, O. (1999): "La transición chilena a la democracia pactada", Estudios Públicos, 74, pp. 79-108.

Guzmán, E. (1993): "Reflexiones sobre el sistema binominal", Estudios Públicos, 51, pp. 303-324.

Huber, J. y R. Inglehart (1995): "Expert interpretations of party space and party location in 42 societies", Party Politics, 1 (1), pp. 73-111.

Huneeus, C. (2002): “¿Dónde se fueron los votantes del PDC?”, Informe 175, disponible en: www. asuntospublicos.cl

(2003): Chile, un país dividido. La actualidad del pasado, Catalonia, Santiago de Chile.

Huneeus, C. y C. Maldonado (2003): “Demócratas y nostálgicos del antiguo régimen. Apoyos a la democracia en Chile", Revista Española de Investigaciones Sociológicas, 103, pp. 9-49.

Joignant, A. (2007). "Modelos, juegos y artefactos. Supuestos, premisas e ilusiones de los estudios electorales y de sistemas de partidos en Chile (1988-2005)", Estudios Públicos, 106, pp. 205-271.

Joignant, A. y P. Navia (2003): “De la política de individuos a los hombres de partido. Socialización, competencia política y penetración electoral de la UDI (1989-2001)", Estudios Públicos, 89, pp. 129-171.

Lipset, S.M. y S. Rokkan (1967): "Cleavage structures, party systems, and voter alignments: an introduction", en S.M. Lipset y S. Rokkan (eds.): Party systems and voter alignments: crossnational perspectives', Free Press, New York, pp. 1-64.

Luna, J.P. y D. Altman (2011): “Uprooted but stable: Chilean parties and the concept of party system institutionalization", Latin American Politics and Society, 53 (2), pp. 1-28. 
Luna, J. y R. Mardones (2010): "Chile: are the parties over?", Journal of Democracy, 21(2), pp. 107-121.

Luna, J. y E. Zechmeister (2005): "Political representation in Latin America: a study of elite-mass congruence in nine countries", Comparative Political Studies, 38 (4), pp. 388-416.

Maillet, A. (2009): "Chile: a case of political cleavage?", trabajo presentado en el 21 Congreso Mundial de IPSA, 12-16 de Julio, Santiago de Chile.

Mainwaring, S. y T.R. Scully (1995): "Introduction: party systems in Latin America", en S. Mainwaring y T.R. Scully (eds.): Building democratic institutions: party systems in Latin America, Stanford University Press, Stanford, pp. 1-34.

Montes, J.E., S. Mainwaring y E. Ortega (2000): "Rethinking the Chilean party systems", Journal of Latin American Studies, 32, pp. 795-824.

Morgenstern, S., J. Polga-Hecinovich y P. Siavelis (2012): “Ni chicha ni limoná: party nationalization in pre and post authoritarian Chile", Party Politics (en prensa).

Navia, P. (2005): "La transformación de votos en escaños: leyes electorales en Chile, 1833-2004", Política y Gobierno, 12 (2), pp. 233-276.

(2006): "Three's company: old and new alignments in Chile's party system", en S. Borzutzky y H. Oppenheim (eds.): After Pinochet: the Chilean road to democracy and the market, University Press of Florida, Gainesville, pp. 43-63.

Navia, P. y M. Schuster (2011): "On the emergence of social and electoral cleavages: age differences in the 2009 presidential election in Chile?", trabajo preparado para la reunión anual de la APSA, 1-4 de septiembre.

Ortega, E. (2003): “Los partidos políticos chilenos: cambio y estabilidad en el comportamiento electoral 1990-2000", Revista de Ciencia Política, XXIII (2), pp. 109-147.

Rabkin, R. (1996): "Redemocratization, electoral engineering, and party strategies in Chile, 1989-1995", Comparative Political Studies, 29 (3), pp. 335-356.

Raymond, C. y B. Barros Feltch (2012): "Parties, cleavages and issue evolution: the case of the religioussecular cleavage in Chile", Party Politics (versión online, publicada el 19 de marzo).

Roberts, K. (2013): "Party systems and democratic divergence in contemporary Latin America", trabajo presentado para la conferencia anual de la APSA, Chicago, 28-31 de agosto.

Roberts, K. y E. Wibbels (1999): "Party systems and electoral volatility in Latin America: a test of economic, institutional, and structural explanations, The American Political Science Review, 93 (3), pp. 575-590.

Ruiz Rodríguez, L. (2005): "Polarization in the Chilean party system: changes and continuities, 1990-1999", Working Paper 236, Institut de Ciències Polítiques i Socials, Universidad Autónoma de Barcelona.

Scully, T.R. (1992): Rethinking the center: party politics in nineteenth and twentieth-century Chile, Stanford University Press, Stanford.

(1995): "Reconstituting party politics in Chile", en S. Mainwaring y T.R. Scully (eds.): Building democratic institutions: party systems in Latin America, Stanford University Press, Stanford, pp. 100-137.

Scully, T.R. y S. Valenzuela (1993): “De la democracia a la democracia. Continuidad y variaciones en las preferencias del electorado y en el sistema de partidos en Chile", Estudios Públicos, 51, pp. 195-228. 
Siavelis, P. (1997): "Continuity and change in the Chilean party system. On the transformational effects of electoral reform", Comparative Political Studies, 30 (6), pp. 651-74.

(2000): "Continuidad y cambio en el sistema partidista chileno: sobre los efectos de transformación de una reforma electoral", Revista de Ciencia Política, XX (2), pp. 82-102.

(2005a): "Los peligros de la ingeniería electoral y de predecir sus efectos", Política, 45, pp. 9-29.

(2005b): "Electoral system, coalition desintegration and the future of Chile's Concertación", Latin American Research Review, 40 (1), pp. 57-82.

Tironi, E. y F. Agüero (1999): “¿Sobrevivirá el nuevo paisaje político chileno?”, Estudios Públicos, 74, pp. 151-168.

Tironi, E., F. Agüero y E. Valenzuela (2001): “Clivajes políticos en Chile: perfil sociológico de los electores de Lagos y Lavín”, Perspectivas en Política, Economía y Gestión, 5 (1), pp. 73-87.

Torcal, M. y S. Mainwaring (2003): "The political recrafting of social bases of party competition: Chile, 1973-95", British Journal of Political Science, 33 (1), pp. 55-84.

Valenzuela, A. (1978): The breakdown of democratic regimes: Chile, John Hopkins University Press, Baltimore.

Valenzuela, A. y J.S. Valenzuela (1983): “Partidos de oposición bajo el régimen autoritario chileno", en M.A. Garretón: Chile 1973-198?, FLACSO, Santiago de Chile.

Valenzuela, A. y P. Siavelis (1991): “Ley electoral y estabilidad democrática. Un ejercicio de simulación para el caso de Chile", Estudios Públicos, 43, pp. 27-64

Valenzuela, J.S. (1995): "Orígenes y transformaciones del sistema de partidos en Chile", Estudios Públicos, 58, pp. 5-80.

(1999): "Reflexiones sobre el presente y futuro del paisaje político chileno a la luz del pasado", Estudios Públicos, 75, pp. 273-290.

(2005): “¿Hay que eliminar el sistema binominal? Una propuesta alternativa”, Política, 45 , pp. 53-67.

Valenzuela, J.S. y T.R. Scully (1997): “Electoral choices and the party system in Chile. Continuities and changes at the recovery of democracy", Comparative Politics 29 (4), pp. 511-527.

Valenzuela, J.S., T.R. Scully y N. Somma (2007): "The enduring presence of religion in Chilean ideological positionings and voter options", Comparative Politics, 40 (1), pp. 1-20.

Zucco, C. (2007): "Where's the bias? A reassessment of the Chilean electoral system", Electoral Studies, 26, pp. 303-314.

Artículos de prensa:

Biobío Chile (7 de octubre de 2013): “Patricio Melero: ‘Dolió que Piñera hablara de cómplices pasivos, se equivocó"', disponible en http://www.biobiochile.cl/2013/10/07/patricio-melero-dolio-quepinera-hablara-de-complices-pasivos-se-equivoco.shtml

El Mercurio (30 de septiembre de 2013): "RN reclama a La Moneda por críticas del ministro Hinzpeter a su sector", disponible en: http://www.emol.com/noticias/nacional/2013/09/30/622220/rnreclama-a-la-moneda-por-criticas-del-ministro-hinzpeter-a-su-sector.html 
El Mercurio (6 de octubre de 2013): "Jovino Novoa: 'Fundar una nueva derecha partiendo de cero es iluso y torpe ${ }^{\prime \prime \prime}$.

La Segunda (30 de septiembre de 2013): "Airada protesta RN-UDI en La Moneda por dichos de Hinzpeter, que acusó 'debilidad ética' de Alianza".

La Tercera, Reportajes (31 de agosto de 2013): “Presidente Sebastián Piñera y su juicio a 40 años del golpe: 'Hubo muchos que fueron cómplices pasivos: que sabían y no hicieron nada o no quisieron saber'".

La Tercera (6 de septiembre de 2013): “En nueva carta, personeros DC emplazan al partido a aclarar rol en el golpe".

Qué Pasa (3 de octubre de 2013): "El Sí/No de la derecha".

Recibido: 19-12-2013

Aceptado:12-04-2014 